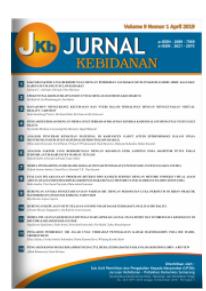

Volume 10 Nomor $1(2020)$ 9-13

JURNAL KEBIDANAN

p-ISSN: 2089-7669 ; e-ISSN: 2621-2870

https://doi.org/10.31983/jkb.v10i1.4883

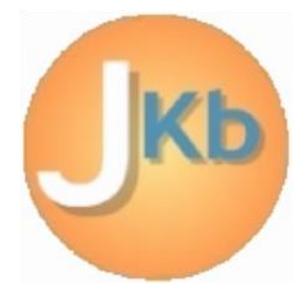

\title{
Discharge Planning on Postpartum Who Has Low Birth Weight (LBW) Babies with The Practice of LBW Babies Care At Home
}

\author{
Ditha Rizky Oktavianti ${ }^{1 *}$, Sri Rahayu ${ }^{2}$, Listyaning Eko Martanti ${ }^{2}$ \\ ${ }^{1}$ UPTD Puskesmas Maliku, Indonesia \\ ${ }^{2}$ Department of Midwifery, Poltekkes Kemenkes Semarang, Indonesia \\ J1. Tjilik Riwit Desa Maliku Baru Pulang Pisau, Kalimantan Tengah, Indonesia \\ Jl. Tirto Agung Pedalangan Banyumanik, Semarang, Jawa Tengah, Indonesia \\ Corresponding author: Ditha Rizky Oktavianti \\ Email: ditha.nezz88@gmail.com
}

Received: July $9^{\text {th }}, 2019$; Revised: September $4^{\text {th }}, 2019$; Accepted: January $29^{\text {th }}, 2020$

\begin{abstract}
Mother have an important role in caring for and nurturing their babies well. It is necessary to provide education to mother and family through discharge planning. Discharge planning is a process that aims to help patients and families in improving or maintaining their health status. The purpose of this research is to know the effect of discharge planning on postpartum mother who has LBW babies against the practice of LBW babies care at home after treatment in dr. Doris Sylvanus hospital. Type of research was quasi-experimental (Pretest-Posttest with control group design). The population is the postpartum who has LBW baby. Sampling using Purpose Sampling technique with treatment group of 16 respondents was given discharge planning with module and 16 respondents were given health education with leaflet. The practice of treating LBW baby at home is assessed after the baby comes home with a checklist. Data analyzed using paired samples t-test and independent samples t-test. The results were dominated by the age group of 20-35 years old, most of them have the level of secondary education and work as housewife. There was an effect of discharge planning on postpartum mother to the practice of infant care LBW with p-value 0.0001. There was an increase of the mean for the control group (3.05) and the treatment group (9.45). The involvement of mothers in care when the baby is still in the hospital and the hospital can give discharge planning about baby care at home before baby LBW is allowed home.
\end{abstract}

Keywords: low birth weight; discharge planning; infant care

\section{Pendahuluan}

Angka Kematian Bayi (AKB) di Indonesia masih tergolong tinggi yaitu 27 per 1.000 kelahiran hidup dibandingkan dengan target MDGs untuk AKB yaitu 23 per 1.000 kelahiran hidup. Angka Kematian Bayi (AKB) di Kalimantan Tengah pada tahun 2016 sebesar 32 per 1.000 kelahiran hidup. Terjadi peningkatan dari tahun 2015 sebesar 25 per 1.000 kelahiran hidup. Salah satu penyumbang terbesar kematian bayi di Kalimantan Tengah adalah BBLR. Berdasarkan data dari Dinas Kesehatan Provinsi Kalimantan Tengah kasus kejadian BBLR meningkat drastis yaitu pada tahun
2015 sebanyak 44.145 kelahiran bayi terdapat 495 bayi BBLR dan menjadi 750 bayi BBLR dari 44.837 kelahiran bayi pada tahun 2016.[1] Data yang diperoleh setelah studi pendahuluan di Ruang Perinatologi RSUD dr. Doris Sylvanus Palangka Raya pada tahun 2017 terdapat sebanyak 359 kelahiran bayi dengan BBLR dan sebanyak 28 bayi BBLR meninggal dunia.

Bayi yang lahir dengan BBLR berisiko kematian 35 kali lebih tinggi dibandingkan dengan bayi yang berat lahirnya diatas 2500 gram.[2] Keluarga khususnya ibu memiliki peran penting dalam merawat dan mengasuh bayinya dengan baik. 
Ibu adalah orang yang paling dekat dengan bayi dan bertanggungjawab dalam merawat bayi. Ibu harus percaya diri dan berani merawat bayinya sendiri, karena dari situlah akan terjadi kontak untuk menciptakan bonding antara ibu dan bayi. [2] Pengetahuan dan sikap ibu tentang perawatan BBLR secara tidak langsung dapat meningkatkan kesehatan BBLR. Selain itu pengetahuan dapat mengubah sikap terhadap sesuatu hal. Sikap adalah penilaian seseorang terhadap stimulus atau objek, dimana sikap merupakan proses kelanjutan setelah seseorang mengetahui,[3] sehingga untuk meningkatkan pengetahuan tersebut maka perlu pemberian edukasi kepada ibu dan keluarga melalui discharge planning. Discharge planning adalah suatu proses yang bertujuan untuk membantu pasien dan keluarga dalam meningkatkan atau mempertahankan derajat kesehatannya. [4]

Discharge planning membantu pasien dan keluarga dalam menetapkan kebutuhan, mengimplementasikan serta mengkoordinasi rencana perawatan yang akan dilakukan setelah pasien pulang dari rumah sakit sehingga dapat meningkatkan atau mempertahankan derajat kesehatannya.[5]

Penatalaksanaan kepulangan bayi BBLR di RSUD dr. Doris Sylvanus Palangka Raya dilakukan dengan pendidikan kesehatan sebelum pulang kepada ibu bayi. Hal tersebut dirasakan kurang begitu optimal mengingat keterbatasan waktu dan keterbatasan informasi yang bisa ditangkap oleh ibu bayi. Beberapa bayi BBLR yang sudah pulang kembali dirawat dengan diagnosa Ikterik, Sepsis dan Hipotermi sehingga setelah bayi BBLR pulang perlu dilakukan follow- up untuk menjamin kelanjutan perawatan bayi BBLR.

\section{Metode Penelitian}

Jenis penelitian ini adalah penelitian kuantitatif dengan metode experimental digunakan rancangan penelitian dengan quasy eksperimental mengunakan Pretest-Posttest with Control Group Design dengan variabel bebas discharge planning dan variabel terikat praktik perawatan bayi BBLR di rumah.

Populasi dalam penelitian ini adalah seluruh ibu nifas yang memiliki bayi BBLR di RSUD dr. Doris Sylvanus Palangka Raya dengan jumlah sebanyak 68 orang pada bulan Februari - Maret 2018. Sampel pada penelitian kali ini berjumlah 16 responden kelompok kontrol dan 16 responden kelompok perlakuan.

Teknik sampling yang digunakan yaitu purpose sampling. Dalam menentukan kelompok kontrol dan kelompok perlakuan, peneliti menggunakan sistem undian urutan responden untuk menghindari subjektifitas dalam penelitian. Instrumen penelitian menggunakan checklist mengenai praktik perawatan bayi BBLR yang meliputi checklist mencuci tangan, checklist perawatan metode kanguru, dan checklist pemberian ASI. Media yang digunakan yaitu modul untuk kelompok perlakuan dan leaflet untuk kelompok kontrol. Teknik pengolahan data yang digunakan peneliti adalah editing, coding, processing (data entry) dan cleaning.

Analisa data menggunakan analisa univarat dan analisa bivariat menggunakan uji Paired Samples T Test dan uji Independent Samples $T$ Test.

\section{Hasil dan Pembahasan}

Tabel 1

Distribusi Frekuensi Karakteristik Responden Berdasarkan Umur, Tingkat Pendidikan dan Pekerjaan.

\begin{tabular}{lcccc}
\hline \multirow{2}{*}{ Variabel } & \multicolumn{4}{c}{ Kelompok } \\
\cline { 2 - 5 } & \multicolumn{2}{c}{ Kontrol } & \multicolumn{2}{c}{ Perlakuan } \\
\cline { 2 - 5 } & F & $\%$ & $\mathrm{f}$ & $\%$ \\
\hline Umur & & & & \\
$<20$ tahun & 2 & 12,5 & 5 & 31,25 \\
$20-35$ tahun & 12 & 75 & 11 & 68,75 \\
$>35$ tahun & 2 & 12,5 & 0 & 0 \\
\hline Tingkat Pendidikan & & & & \\
Pendidikan Dasar & 2 & 12,5 & 2 & 12,5 \\
Pendidikan Menengah & 9 & 56,25 & 13 & 81,25 \\
Pendidikan Tinggi & 5 & 31,25 & 1 & 6,25 \\
\hline
\end{tabular}




\begin{tabular}{lccccc}
\hline \multirow{2}{*}{ Variabel } & \multicolumn{3}{c}{ Kelompok } \\
\cline { 2 - 5 } & \multicolumn{3}{c}{ Kontrol } & \multicolumn{3}{c}{ Perlakuan } \\
\cline { 2 - 5 } Pekerjaan & $\mathrm{F}$ & $\%$ & $\mathrm{f}$ & $\%$ \\
Bekerja & 6 & 37,5 & 0 & 0 \\
IRT & 10 & 62,5 & 16 & 100 \\
\hline Total & 16 & 100 & 16 & 100 \\
\hline
\end{tabular}

Tabel 2

Distribusi Frekuensi Sebelum Pemberian Discharge Planning Terhadap Praktik Perawatan Bayi BBLR

\begin{tabular}{lcc}
\hline \multicolumn{1}{c}{ Praktik Perawatan Bayi BBLR } & Kelompok Kontrol & Kelompok Perlakuan \\
\hline Mean & 76,87 & 73,82 \\
Median & 77,22 & 73,75 \\
SD & 11,43 & 6,82 \\
Minimum & 57,57 & 61,25 \\
Maksimum & 90,00 & 92,50 \\
\hline
\end{tabular}

Tabel 3

Distribusi Frekuensi Setelah Pemberian Discharge Planning Terhadap Praktik Perawatan Bayi BBLR

\begin{tabular}{lcc}
\hline \multicolumn{1}{c}{ Praktik Perawatan Bayi BBLR } & Kelompok Kontrol & Kelompok Perlakuan \\
\hline Mean & 79,92 & 83,28 \\
Median & 80,62 & 83,12 \\
SD & 10,85 & 7,37 \\
Minimum & 61,25 & 66,25 \\
Maksimum & 93,75 & 97,50 \\
\hline \multicolumn{1}{c}{ Tabel 1 menunjukkan } & & \\
\hline
\end{tabular}

Tabel 1 menunjukkan bahwa distribusi frekuensi umur pada kelompok kontrol di dominasi 20 - 35 tahun sebanyak 12 responden (75\%), sedangkan pada kelompok perlakuan untuk usia $<20$ tahun sebanyak 5 responden $(31,25 \%)$ dan usia $20-35$ tahun sebanyak 11 responden $(68,75 \%)$. Untuk tingkat pendidikan pada kelompok kontrol sebanyak 2 responden $(12,5 \%)$ memiliki tingkat pendidikan dasar, 9 responden $(56,25 \%)$ memiliki tingkat pendidikan menengah dan 5 responden $(31,25 \%)$ memiliki tingkat pendidikan tinggi sedangkan untuk kelompok perlakuan didominasi tingkat pendidikan menengah sebanyak 13 responden $(81,25 \%)$.

Variabel pekerjaan, pada kelompok kontrol 10 responden $(62,5 \%)$ adalah IRT sedangkan pada kelompok perlakuan 16 responden (100\%) adalah IRT.

Nilai rata-rata praktik perawatan bayi BBLR di rumah saat pretest pada kelompok kontrol 76,87 dan nilai rata-rata saat posttest pada kelompok kontrol 79,92. Hasil penelitian ini didapatkan hasil bahwa nilai rata-rata posttest mengalami peningkatan. Responden diberikan pendidikan kesehatan dengan media leaflet. Media leaflet menyampaikan materi tentang perawatan bayi BBLR di rumah yang didukung oleh gambargambar. Hasil penelitian ini sesuai dengan penelitian yang menyatakan bahwa rata-rata nilai pengetahuan responden sebelum diberikan pendidikan kesehatan dengan media leaflet sebesar 18,89 dan sesudah diberikan pendidikan kesehatan dengan media leaflet sebesar 24,79. [8]

Tujuan umum pendidikan kesehatan yaitu terjadinya perubahan pengetahuan, sikap dan tingkah laku individu, keluarga, kelompok khusus, dan masyarakat dalam membina serta memelihara perilaku hidup sehat serta berperan aktif dalam upaya mewujudkan derajat kesehatan yang optimal. [7] Tujuan pendidikan kesehatan menurut adalah untuk mengubah pengetahuan, sikap dan tingkah laku. [6]

Nilai rata-rata pretest responden 73,82 dan setelah diberikan discharge planning tentang perawatan bayi BBLR di rumah nilai rata-rata posttest 83,28 . Terdapat peningkatan nilai rata-rata sebesar 9,46.

Berdasarkan model konseptual Orem, discharge planning dalam penelitian ini termasuk kategori sistem supportif dan edukatif yaitu responden mampu melakukan perawatan bayi secara mandiri setelah diberikan informasi tentang cara perawatan metode kanguru (PMK), cara pemberian ASI dan pencegahan infeksi.[7] Ibu BBLR dengan didampingi sejak di rumah sakit dan dibekali modul perawatan metode kanguru memiliki wawasan dan kepercayaan diri serta keterampilan. 
Tabel 4

Pengaruh Praktik Perawatan Bayi BBLR di Rumah Sebelum dan Sesudah pada kelompok kontrol dan kelompok perlakuan

\begin{tabular}{lccccc}
\hline \multicolumn{1}{c}{ Kelompok } & Mean \pm S.D & Median & Min & Max & Nilai Sig. (2-tailed) \\
\hline $\begin{array}{l}\text { Pretest } \\
\text { Kontrol }\end{array}$ & $76,87 \pm 11,43$ & 79,37 & 57,50 & 90,00 & 0,0001 \\
$\begin{array}{l}\text { Posttest } \\
\text { Kontrol }\end{array}$ & $79,92 \pm 10,85$ & 80,62 & 61,25 & 93,75 & \\
\hline $\begin{array}{l}\text { Pretest } \\
\text { Perlakuan }\end{array}$ & $73,82 \pm 6,82$ & 73,75 & 61,25 & 92,50 & 0,0001 \\
$\begin{array}{l}\text { Posttest } \\
\text { Perlakuan }\end{array}$ & $83,28 \pm 7,37$ & 83,13 & 66,25 & 97,50 & \\
\hline
\end{tabular}

* Uji Paired Sample T-Test

Tabel 5

Pengaruh praktik perawatan bayi BBLR pada kelompok kontrol dan kelompok perlakuan.

\begin{tabular}{lcccc}
\hline \multicolumn{1}{c}{ Variabel } & Kelompok & Mean & SD & Nilai Sig. (2-tailed) \\
\hline Nilai Rata-rata praktik perawatan & Kontrol & 3,05 & 1,88 & 0,0001 \\
\cline { 2 - 5 } BBLR & Perlakuan & 9,45 & 4,06 & 0,0001 \\
\hline
\end{tabular}

*uji Independent Samples T-test

Kesulitan ibu dalam merawat bayi prematur di rumah juga berkaitan dengan masih kurangnya keterlibatan ibu selama perawatan di rumah sakit. Pendampingan dan pemberian modul efektif meningkatkan kemandirian ibu untuk merawat bayi BBLR setelah pulang dari rumah sakit. [8]

Penelitian tentang pemberian discharge planning terhadap kesiapan pulang pasien bedah abdomen, dengan hasil uji wilcoxon signed rank test dan didapatkan hasil $\mathrm{Z}$ hitung sebesar -2,371 dengan signifikansi sebesar 0,018 yang menunjukkan hasil bahwa discharge planning memberikan pengaruh yang positif. [5]

Tabel analisis bivariat menunjukkan terdapat peningkatan nilai rata-rata praktik responden sebesar 3,05 dan nilai Sig. (2 tailed) sebesar 0,0001 $(\mathrm{p}<0,05)$, itu artinya ada pengaruh pemberian pendidikan kesehatan terhadap praktik perawatan bayi BBLR di rumah. Hal ini didukung dengan penelitian lain bahwa perlakuan terhadap responden penelitian berupa pendidikan kesehatan dengan diberikan leaflet mempengaruhi pengetahuan ibu menjadi lebih baik. [9]

Kemudian untuk kelompok perlakuan, menunjukkan terdapat peningkatan nilai rata-rata praktik responden sebesar 9,46 dan nilai Sig. (2 tailed) sebesar $0,0001 \quad(\mathrm{p}<0,05)$, maka Ha diterima, itu artinya ada pengaruh pemberian discharge planning terhadap praktik perawatan bayi BBLR di rumah.

Discharge planning memberikan pengaruh bermakna terhadap perawatan BBLR di rumah secara statistik dan praktis. Penelitian ini sejalan dengan penelitian sebelumnya yang menyatakan bahwa pendidikan kesehatan yang diberikan dalam discharge planning akan sangat membantu ibu dalam melakukan perawatan BBLR dirumah serta memperlihatkan kesiapan keluarga dalam perawatan bayi dan membantu dalam mendukung pemberian ASI Ekslusif untuk pertumbuhan dan perkembangan bayi optimal. Selain itu, hasil penelitian setelah diberikan discharge planning tingkat stres ibu menjadi lebih berkurang daripada ibu yang tidak diberikan discharge planning. [10]

Penelitian lain juga menyatakan bahwa pentingnya dilakukan discharge preparation yang berkaitan dengan strategi koping ibu yang memiliki BBLR. Manajemen koping ibu dibutuhkan untuk mengatasi stress yang mungkin muncul pada saat perawatan BBLR di RS. Banyak ibu menggunakan strategi manajemen koping yang berfokus pada emosi dan ibu lainnya berfokus pada metode pemecahan masalah. Discharge planning dibutuhkan sebagai bagian dari manajemen koping untuk ibu yang memiliki BBLR. [11]

Keterlambatan pelaksanaan Discharge Planning awal ditemukan hambatan berkaitan dengan banyak faktor sehingga ditemukan perawatan ulang di rumah sakit untuk BBLR yang sudah pulang ke rumah. Beberapa hal yang berpengaruh pada early discharge planning adalah kemampuan mengisap bayi, penatalaksanaan awal pada kasus pembedahan dan pengetahuan orang tua yang adekuat. [12] 
Analisa pengaruh praktik perawatan bayi BBLR pada kelompok kontrol dan kelompok perlakuan bertujuan untuk membuktikan ada tidaknya perbedaan antara kelompok kontrol yang diberikan pendidikan kesehatan dengan media leaflet dan kelompok perlakuan yang diberikan discharge planning dengan media modul. Berdasarkan hasil uji analisis independent samples t-test terhadap hasil praktik perawatan bayi BBLR pada kelompok kontrol dan perlakuan, diperoleh nilai mean pada kelompok kontrol sebesar 3,05 dan pada kelompok perlakuan 9,45 dengan nilai Sig. (2-tailed) 0,0001 (nilai $\mathrm{p}<0,05$ ) maka artinya ada perbedaan yang signifikan antara kelompok kontrol dan kelompok perlakuan.

Pelaksanaan discharge planning pada ibu dan keluarga sebelum bayi BBLR keluar dari ruang perinatologi di rumah sakit sangat membantu ibu dan keluarga agar dapat memberikan perawatan dasar untuk bayi BBLR seperti perawatan kanguru, pemberian asi eksklusif, mandi, dan pemantauan suhu tubuh. Ibu dan keluarga juga harus dapat mengenali tanda-tanda bahaya pada bayi, gejala awal penyakit berbahaya dan bagaimana mengelolanya. Hal ini memungkinkan mereka merasa berguna dan mendapatkan pengalaman dalam menangani bayi BBLR. [11]

\section{Simpulan}

Distribusi frekuensi praktik perawatan bayi BBLR pada kelompok kontrol saat pretest memiliki nilai 76,87 dan saat posttest memiliki nilai 79,92 . Sedangkan pada kelompok perlakuan saat pretest memiliki nilai 73,82 dan saat posttest memiliki nilai 83,28. Ada pengaruh discharge planning pada ibu nifas yang memiliki bayi BBLR terhadap praktik perawatan bayi BBLR di rumah pasca perawatan di RSUD dr. Doris Sylvanus Palangka Raya.

\section{Daftar Pustaka}

[1] Dinkes Provinsi Kalimantan Tengah, Profil Kesehatan Kalimantan Tengah. Palangka Raya: Dinas Kesehatan Provinsi Kalimantan
Tengah, 2016.

[2] A. Proverawati, Berat Badan Lahir Rendah (BBLR) dan Pijat Bayi. Yogyakarta: Nuha Medika, 2010.

[3] S. Notoatmodjo, Pengantar Pendidikan Kesehatan dan Ilmu Perilaku. Yogyakarta: Andi Offset, 2010.

[4] Association Discharge Planning, "Discharge Planning," 2008. [Online]. Available: http;//www.dischargeplanning.org.au//index.h ttp. [Accessed: 18-Dec-2017].

[5] M. Siahaan, "Pengaruh Discharge Planning yang Dilakukan Perawat Terhadap Kesiapan Pasien Pasca Bedah Abdominal Menghadapi Kepulangan di RSUP H. Adam Malik Medan," Medan, 2009.

[6] S. Fitriani, Promosi Kesehatan. Yogyakarta: Graha Ilmu, 2011.

[7] A. Murwani, Pengantar Konsep Dasar Keperawatan. Yogyakarta: Fitramaya, 2008.

[8] S. Rahayu, Runjati, and I. Ariyanti, "Pengaruh Pendampingan dan Pemberian Modul Kangaro Mother Care terhadap Kemandirian Ibu Nifas Merawat BBLR di Rumah," J. Ilm. Bidan, vol. I, no. 3, pp. 55-60, 2016.

[9] Y. R. A. Harahap and A. N. Radityo, "Pengaruh Pemberian Leaflet Dan Penjelasan Terhadap Pengetahuan Ibu Mengenai Pelaksanaan Metode Kanguru Pada Bayi Berat Lahir Rendah,” J. Kedokt. Diponegoro, vol. 6, no. 2, pp. 357-365, 2017.

[10] A. Bostanabad, M. Gharehbaghi, and S. Elmabad, "Effect of discharge planning ptogram on stress of preterm infant mothers in NICU," Iran. J. Pediatr. Nurshing, vol. 2, no. 1, pp. 60-68, 2015.

[11] E. S. Tambunan, H. Pratomo, E. N. Hadi, and Y. Rustina, "Mothers' Coping Strategies in Preparing for the Discharge of Low Birth Weight Infants from a Perinatology Ward," Aust. J. Basic Appl. Sci., vol. 11, no. December, pp. 54-63, 2017.

[12] A. J. Anand et al., "Early discharge planning in preterm low birth weight babies: A quality improvement project," Proc. Singapore Healthc., vol. 26, no. 2, pp. 98-101, 2017. 